\title{
The Position of the Polycystic Kidney Disease 1 (PKD1) Gene Mutation Correlates with the Severity of Renal Disease
}

\author{
SANDRO ROSSETTI,* SARAH BURTON, ${ }^{\dagger}$ LANA STRMECKI, * GREGORY R. POND, \\ JOŚE L. SAN MILLÁN, ${ }^{\S}$ KLAUS ZERRES, ${ }^{\text {II }}$ T. MARTIN BARRATT, ${ }^{\mid}$SEZA OZEN, ${ }^{\prime}$ \\ VICENTE E. TORRES, ${ }^{*}$ ERIK J. BERGSTRALH, ${ }^{\dagger}$ CHRISTOPHER G. WINEARLS, ${ }^{\dagger}$ and \\ PETER C. HARRIS* \\ *Division of Nephrology and ${ }^{*}$ Section of Biostatistics, Mayo Clinic, Rochester, Minnesota; ${ }^{*}$ Renal Unit, The \\ Oxford Radcliffe Hospital, Oxford, United Kingdom; ${ }^{\S}$ Unidad de Genética Molecular, Hospital Ramón y \\ Cajal, Madrid, Spain; "Institute für Human Genetik, Universitütsklinikum der RWTH Aachen, Aachen, \\ Germany; 'Institute of Child Health, London, United Kingdom; ${ }^{*}$ Department of Pediatric Nephrology, \\ Hacettepe University, Ankara, Turkey.
}

\begin{abstract}
The severity of renal cystic disease in the major form of autosomal dominant polycystic kidney disease (PKD1) is highly variable. Clinical data was analyzed from 324 mutation-characterized PKD1 patients (80 families) to document factors associated with the renal outcome. The mean age to end-stage renal disease (ESRD) was $54 \mathrm{yr}$, with no significant difference between men and women and no association with the angiotensin-converting enzyme polymorphism. Considerable intrafamilial variability was observed, reflecting the influences of genetic modifiers and environmental factors. However, significant differences in outcome were also found among families, with rare examples of unusually late-onset PKD1. Possible phenotype/genotype correla-
\end{abstract}

Autosomal dominant polycystic kidney disease (ADPKD) is the most common monogenetic nephropathy (frequency, $1 / 1000$ ) and an important cause of end-stage renal disease (ESRD), accounting for 5 to $8 \%$ of patients requiring renal replacement therapies (1). The disease is progressive, with cyst development and expansion typically resulting in ESRD in late middle age. Linkage analyses in ADPKD families have revealed genetic heterogeneity with two genes, PKDI (chromosomal region 16p13.3) and PKD2 (4q21-q23) identified and characterized (2-5). The protein products of $P K D 1$ and $P K D 2$, polycystin-1 and polycystin-2, respectively, share sequence homology and may form components of a receptor/channel complex $(5,6)$. Polycystin-2 is similar to, and can function as, an ion channel subunit, with nonselective cation permeability $(6-8)$. Polycystin-1 is predicted to have a receptor-like structure, may be involved in cell:cell/matrix interactions $(9,10)$, and may have a regulatory role over a polycystin channel (6).

Received October 23, 2001. Accepted December 22, 2001.

Correspondence to: Dr. Peter C. Harris, 760 Stabile Building, Mayo Clinic, 200 First Street SW, Rochester, MN 55905. Phone: 507-266-0541; Fax: 507-266-4071; E-mail: harris.peter@mayo.edu

$1046-6673 / 1305-1230$

Journal of the American Society of Nephrology

Copyright (๑) 2002 by the American Society of Nephrology

DOI: 10.1097/01.ASN.0000013300.11876.37 tions were evaluated by estimating the effects of covariants on the time to ESRD using proportional hazards models. In the total population, the location of the mutation (in relation to the median position; nucleotide 7812), but not the type, was associated with the age at onset of ESRD. Patients with mutations in the 5' region had significantly more severe disease than the 3 ' group; median time to ESRD was 53 and $56 \mathrm{yr}$, respectively $(P=0.025)$, with less than half the chance of adequate renal function at $60 \mathrm{yr}$ (18.9\% and $39.7 \%$, respectively). This study has shown that the position of the PKDl mutation is significantly associated with earlier ESRD and questions whether PKD1 mutations simply inactivate all products of the gene.

The basic defect in ADPKD could be in polycystin-regulated intracellular $\mathrm{Ca}^{2+}$ levels (11).

The presentation of ADPKD is highly variable, with rare cases diagnosed in utero with massively enlarged and cystic kidneys $(12,13)$, and $25 \%$ of cases have adequate renal function at $70 \mathrm{yr}$ (14). Part of the phenotypic variability is due to the genetic heterogeneity, with the more common PKD1 (accounting for approximately $85 \%$ of cases; reference 15 ) associated with significantly more severe disease (ESRD occurring on average at $53 \mathrm{yr}$ compared with 69 for PKD2; reference 16). However, evidence of significant intrafamilial phenotypic variation, especially evident in pedigrees of early onset cases but also seen in the typical population, suggests that modifying factors (as well as the environment) influence the disease course (12,17-19). Data suggesting that the angiotensin-converting enzyme (ACE) insertion/deletion polymorphism may be such a modifier in ADPKD has been described (20,21).

Despite the intrafamilial variability in ADPKD there is evidence that the germline mutation may influence the phenotype. Significant interfamilial phenotypic differences have been described, and clinically mild PKD1 families documented (22-24). Furthermore, it has been suggested that the location of the PKD2 mutation influences the clinical outcome (25). An anecdotal association of a specific mutation in three families with early onset disease and/or associated vascular complications has also been reported (26). In other genetic disorders 
with a variable presentation, careful analysis of large genetically defined populations has demonstrated correlations between phenotype and the type and/or position of the mutation (27).

Until recently, the size and complexity of PKDl has precluded mutation analysis of the whole gene; hence, comprehensive genotype/phenotype correlations have not been possible. We have now overcome the problems associated with analysis of $P K D 1$ and have described a mutation screen of the entire gene (28). That study showed a wide variety of different mutations spread throughout the gene, although they were significantly more common in the 3 ' compared with the $5^{\prime}$ half. We describe here an analysis of renal disease in this mutationcharacterized population and show, despite significant intrafamilial variability, that the location of the mutation is a significant indicator of disease severity.

\section{Materials and Methods}

\section{PKD1 Pedigrees}

The proband from each family was recruited through the Oxford Renal Unit (68 pedigrees), other adult nephrology departments (5 pedigrees), or various pediatric nephrology units (7 pedigrees). All individuals involved in the study gave informed consent, and the project had ethics committee approval. All probands had ADPKD by defined ultrasound criteria (29). Family histories were taken, and all available family members contacted. Medical histories and blood samples for DNA isolation were collected from family members wishing to take part in the study. Where possible, clinical details were verified from medical records or death certificates. Abdominal ultrasound was organized for at-risk patients who wished to be diagnosed. The onset of ESRD was defined as the time when renal replacement therapy began or death from uremia occurred. Serum creatinine (SC; $\mu \mathrm{mol} / \mathrm{L}$ ) measurements were used to assess renal function in patients not having ESRD. Hypertension was defined as when hypertensive therapy was required.

\section{Clinical Details of PKD1 Pedigrees with Atypical Presentations}

Atypical renal presentations of PKD1 were defined as early onset in cases with enlarged hyperechoic kidneys before $2 \mathrm{yr}$ of age, or late onset in patients with adequate renal function at $>75 \mathrm{yr}$.

\section{Early Onset}

- P117: The clinical details of members of this pedigree have previously been described in reference 19 (mutation Y3818X).

- P118: The proband died immediately postnatally with pulmonary hypoplasia and grossly enlarged kidneys. The mother was diagnosed by ultrasound examination and had normal renal function at $25 \mathrm{yr}$ (8126ins20).

- P148: The proband was diagnosed in utero with greatly enlarged kidneys. At $19 \mathrm{yr}$, her kidneys remain enlarged but renal function is normal. Her sister has impaired function (SC, $218 \mu \mathrm{mol} / \mathrm{L}$ ) at 14 $\mathrm{yr}$ and is hypertensive. Their mother (46 yr) has normal renal function but enlarged kidneys and polycystic liver disease. The aunt (46 yr) has normal kidney function and an affected daughter with normal function (18 yr). The affected grandmother started dialysis at $54 \mathrm{yr}(\mathrm{E} 2771 \mathrm{~K})$. Reference 30.

- P159: The proband was diagnosed at $2 \mathrm{yr}$ with gross hematuria and ultrasound examination showing multiple cysts and renal enlargement. His father has multiple renal cysts $(30 \mathrm{yr})(\mathrm{S} 75 \mathrm{~F})$.
- P169: The proband was diagnosed in the first week of life with enlarged kidneys but has normal renal function at $7 \mathrm{yr}$. Her sister ( $2 \mathrm{yr}$ ) and mother $(30 \mathrm{yr})$ have asymptomatic ADPKD. The aunt has hypertension, and affected grandmother died from metastases of renal carcinoma at $49 \mathrm{yr}$. The affected great-grandmother died of chronic renal failure at $40 \mathrm{yr}$ (7211ins7).

- P190: The proband presented at birth with enlarged kidneys, had early hypertension, and has slowly progressing renal failure at 15 yr. The affected father has multiple renal cysts but normal renal function (39 yr) and a negative family history (8507ins12).

\section{Late Onset}

- P499: The proband was diagnosed by intravenous pyelography after minor hematuria at $70 \mathrm{yr}$ and ultimately developed ESRD at 80 (S225X). He has an affected son (49 yr) with normal renal function (SC, $78 \mu \mathrm{mol} / \mathrm{L})$.

- P228: The proband had a SC of $130 \mu \mathrm{mol} / \mathrm{L}$ at $81 \mathrm{yr}$, and her affected children and niece had only slightly elevated SC of 135 , 121 , and $111 \mu \mathrm{mol} / \mathrm{L}$ at 63, 57, and $46 \mathrm{yr}$, respectively (L2816P).

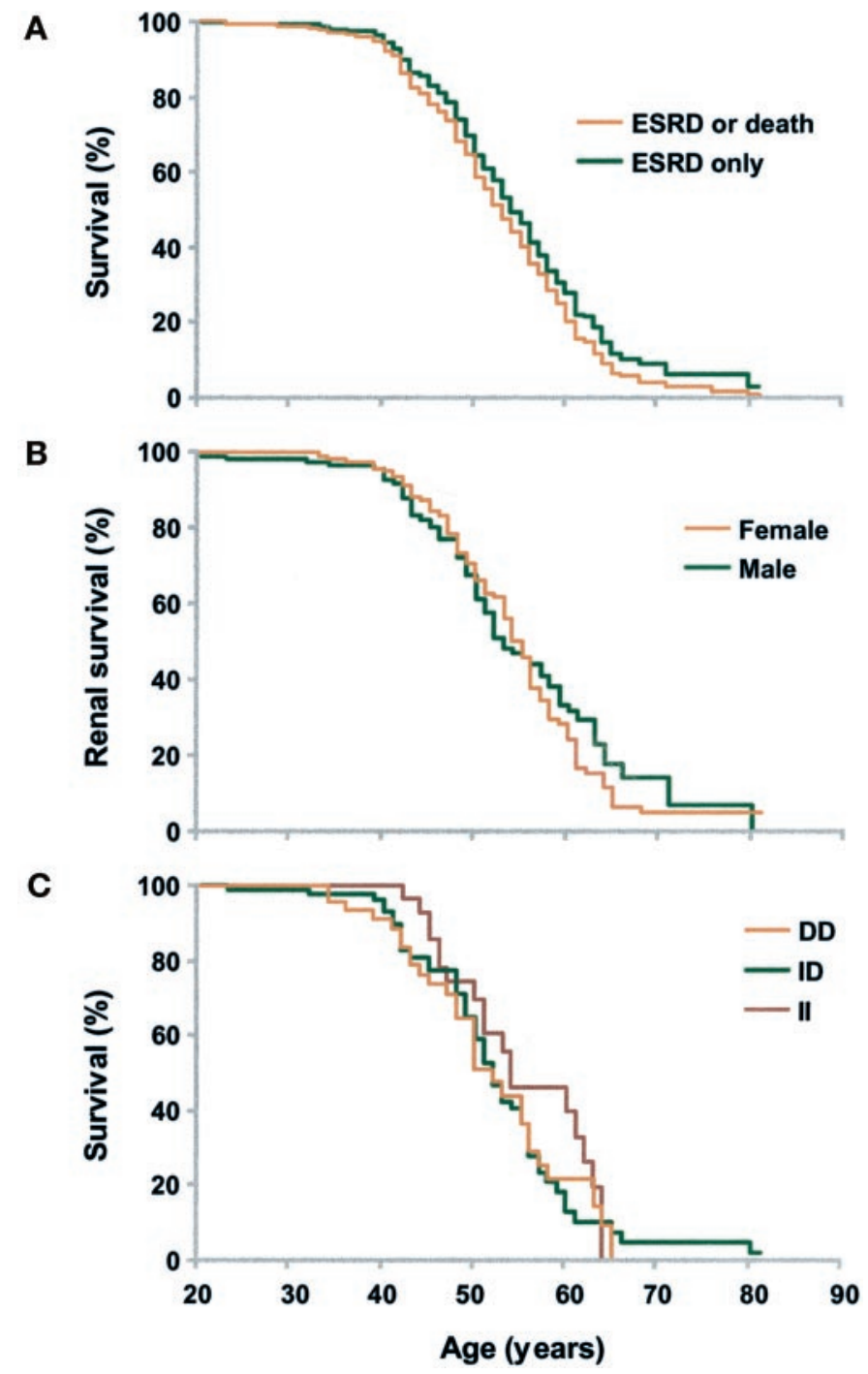

Figure 1. (A) Cumulative probabilities of survival to end-stage renal disease (ESRD) or ESRD or death. Neither gender (B) nor the angiotensin-converting enzyme (ACE) insertion/deletion (I/D) polymorphism (C) have a significant influence on renal survival. 


\section{Molecular Data}

DNA isolation procedures, mutation screening methods, and the mutations identified in these pedigrees have been described elsewhere (28). Mutations were defined as follows: truncating (nonsense, frameshifting deletions, insertions, or splice events); in-frame (insertions and splicing events that maintain the reading frame, ranging from loss of a single codon to deletion of 97 residues; reference 28); or missense substitutions.

\section{Analyses of the ACE Polymorphism}

The ACE insertion/deletion (I/D) polymorphism was analyzed by PCR as described previously (20). The amplified product was $190 \mathrm{bp}$ (D allele) or 490 bp (I allele). An additional insertion-specific amplification was performed in all apparent $\mathrm{D} / \mathrm{D}$ individuals to prevent mistyping (20). PCR products were visualized by ethidium bromide staining after electrophoresis in $1.75 \%$ agarose gels.

\section{Statistical Analyses}

Time from birth to ESRD (or death) was computed by using the Kaplan-Meier method. The effects of covariates on time to ESRD was tested by using the univariate Cox proportional hazards model or the log-rank test for continuous or categorical variables, respectively (31).
Potential correlation within members of the same family was accounted for and significance tested using a robust variance estimator (32). The functional form of the relationship between nucleotide location and risk of ESRD was investigated by plotting the Martingale residuals (from a Cox model with no covariates) with a local regression (LOESS) smoother, against nucleotide location (33). All tests were two-sided, and a robust $P<0.05$ was considered statistically significant. In Figure 2 , the running average of age at ESRD is based on the best fitting cubic spline function of the age versus nucleotide relationship.

\section{Results}

\section{The PKD1 Population}

Information about renal status was collected on 324 PKD1 patients from 80 different pedigrees in which the $P K D 1 \mathrm{mu}-$ tation was characterized (28). The age at the onset of ESRD was known for 152 patients, and the age at death, not due to ESRD or for unknown reasons, was documented for an additional 36 patients. The remaining 136 patients had adequate renal function, and their age and $\mathrm{SC}$ were recorded. Of the total population, 177 (54.6\%) were women and 147 (45.4\%) were

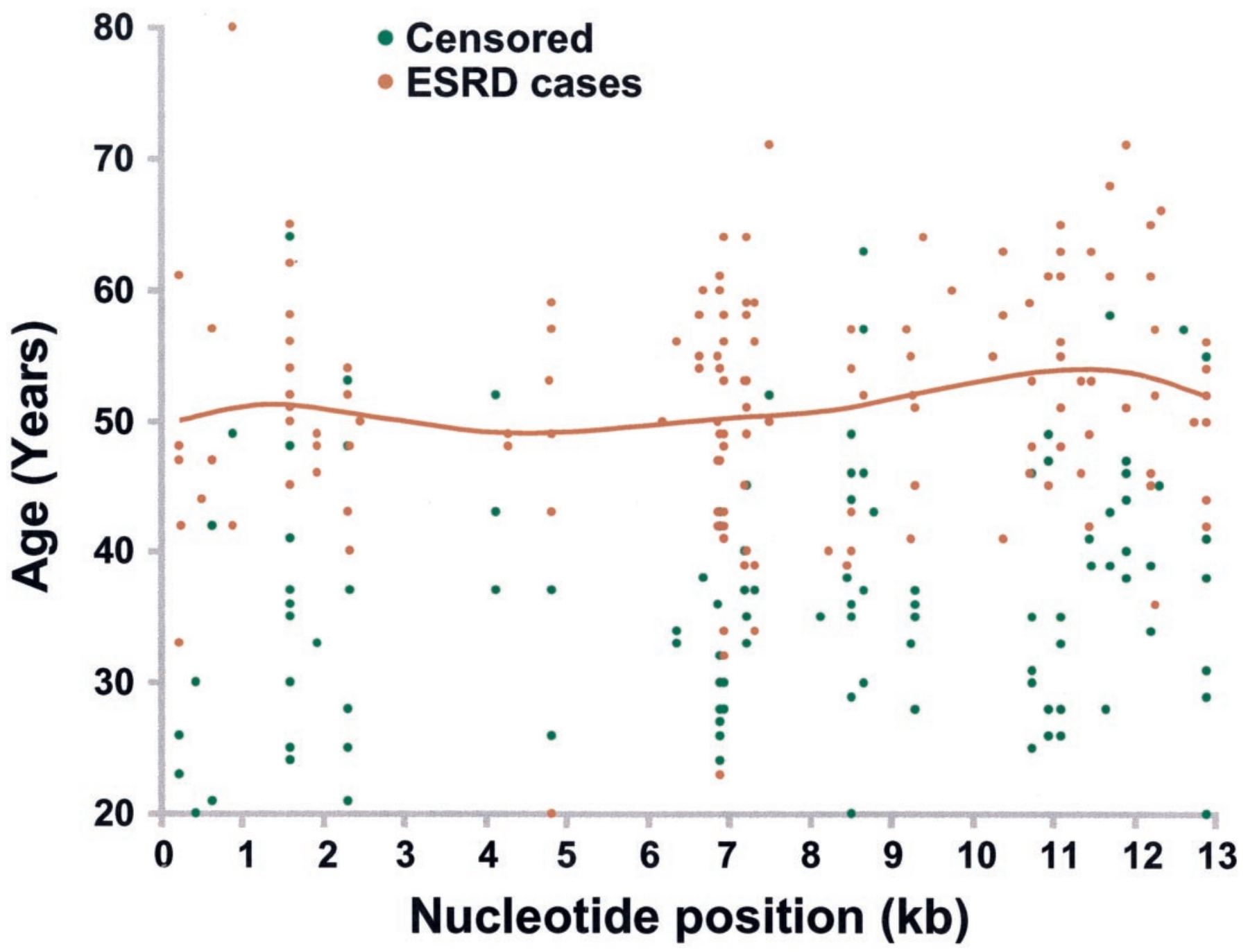

Figure 2. Plot of age at onset of ESRD (orange) or age of patients with renal function (censored; green) compared with the position of the mutation along the transcript. A running average of age at onset of ESRD is plotted using only the patients with ESRD (orange). 
men. There were 207 patients whose BP status was known, of whom 147 (71.0\%) were hypertensive.

To characterize the severity of disease in the PKD1 population and to compare it with other PKD1 populations defined by linkage, survival curves from birth until ESRD, or ESRD or death, were computed by using the Kaplan-Meier method. The median age at the onset of ESRD was $54 \mathrm{yr}$, and ESRD or death was 53 yr (Figure 1A). As we wished to determine what factors influenced the severity of renal disease, the age at onset of ESRD was used as the endpoint in all other survival plots. Comparison of genders showed no significant difference (Figure $1 \mathrm{~B}$ and Table 1). To see if the ACE polymorphism was associated with disease severity in this mutation-defined PKD1 population, this marker was typed in 216 patients from whom DNA was available. Of these, 64 were DD (29.6\%), 108 ID (50.0\%), and $44 \mathrm{II}(20.4 \%)$, giving allele frequencies of $54.6 \%$ (D) and $45.7 \%$ (I) and a distribution in Hardy-Weinberg equilibrium. Renal survival analysis showed no significant difference among the three haplotypes (Figure 1C and Table 1).

\section{Intrafamilial and Interfamilial Variability}

To analyze the extent to which the severity of renal disease varied within families, the age at onset of ESRD, or the age of patients with renal function (censored data), was plotted against the position of the mutation within the transcript (Figure 2). This figure illustrates that the severity of disease varies considerably between patients with mutations in similar locations, including those within the same family (which are plotted at the same nucleotide position). This intrafamilial variability probably reflects a combination of genetic modification and environmental factors. To determine if the renal outcomes among families were significantly different, a Kaplan-Meier renal survival plot was generated for the four largest families, with 17 or more patients available for study (Figure 3A; Table $1)$. The log-rank test showed a significant difference in time to ESRD in these families $(P=0.013)$, with one more severe than the average and three with milder disease. These data indicate that characteristics of the mutation itself may influence the disease presentation. Genetic modification factors may, how-

Table 1. Details of renal survival analyses ${ }^{\mathrm{a}}$

\begin{tabular}{|c|c|c|c|c|c|}
\hline Variable & Patients (Families) & $\begin{array}{l}\% \text { Renal Survival } \\
50 \mathrm{yr}\end{array}$ & $\begin{array}{l}\% \text { Renal Survival } \\
60 \mathrm{yr}\end{array}$ & $\begin{array}{l}\text { Median Age at } \\
\text { ESRD }\end{array}$ & $\begin{array}{l}\text { Robust } P \\
\text { value (df) }\end{array}$ \\
\hline Overall & $324(80)$ & 64.3 & 27.9 & 54 & \\
\hline \multicolumn{6}{|l|}{ Gender } \\
\hline men & 147 & 61.8 & 32.1 & 53 & 0.57 \\
\hline women & 177 & 66.4 & 24.8 & 55 & (1) \\
\hline \multicolumn{6}{|l|}{$\mathrm{ACE}$} \\
\hline II & 44 & 70.0 & 40.0 & 54 & 0.26 \\
\hline ID & 108 & 59.4 & 13.4 & 52 & (2) \\
\hline DD & 64 & 51.3 & 22.1 & 52 & \\
\hline \multicolumn{6}{|l|}{ Largest families } \\
\hline 1 & 26 & 80.7 & 33.5 & 56 & $0.013^{b}$ \\
\hline 13 & 20 & 76.8 & 48.0 & 60 & (3) \\
\hline $17 \& 17 \mathrm{~A}$ & 17 & 38.5 & 12.8 & 43 & \\
\hline 125 & 19 & 91.7 & 42.8 & 56 & \\
\hline \multicolumn{6}{|l|}{ Mutation type } \\
\hline truncating & $219(54)$ & 65.1 & 27.8 & 54 & 0.40 \\
\hline in-frame & $40(11)$ & 44.8 & 24.9 & 50 & (2) \\
\hline missense & $65(15)$ & 75.0 & 31.0 & 56 & \\
\hline \multicolumn{6}{|c|}{ Nucleotide location median } \\
\hline$<7812$ & $162(36)$ & 55.8 & 18.9 & 53 & 0.025 \\
\hline$>=7812$ & $162(44)$ & 74.5 & 39.7 & 56 & (1) \\
\hline \multicolumn{6}{|c|}{$\begin{array}{l}\text { Mutation type and location } \\
\text { truncating }\end{array}$} \\
\hline$<7812$ & $140(30)$ & 60.3 & 21.8 & 54 & 0.094 \\
\hline$>=7812$ & $79(24)$ & 74.1 & 39.7 & 57 & (1) \\
\hline \multicolumn{6}{|l|}{ in-frame } \\
\hline$<7812$ & $10(3)$ & 13.0 & 0.0 & 50 & 0.021 \\
\hline$>=7812$ & $30(8)$ & 63.3 & 43.7 & 53 & (1) \\
\hline \multicolumn{6}{|l|}{ missense } \\
\hline$<7812$ & $12(4)$ & 42.9 & 0.0 & 47 & 0.058 \\
\hline$>=7812$ & $53(11)$ & 81.6 & 39.3 & 57 & (1) \\
\hline
\end{tabular}

${ }^{\mathrm{a}} \mathrm{ESRD}$, end-stage renal disease; ACE, angiotensin-converting enzyme.

${ }^{\mathrm{b}} P$ value from standard Cox model with nonrobust variance estimate (few families to reliably estimate robust variance). 


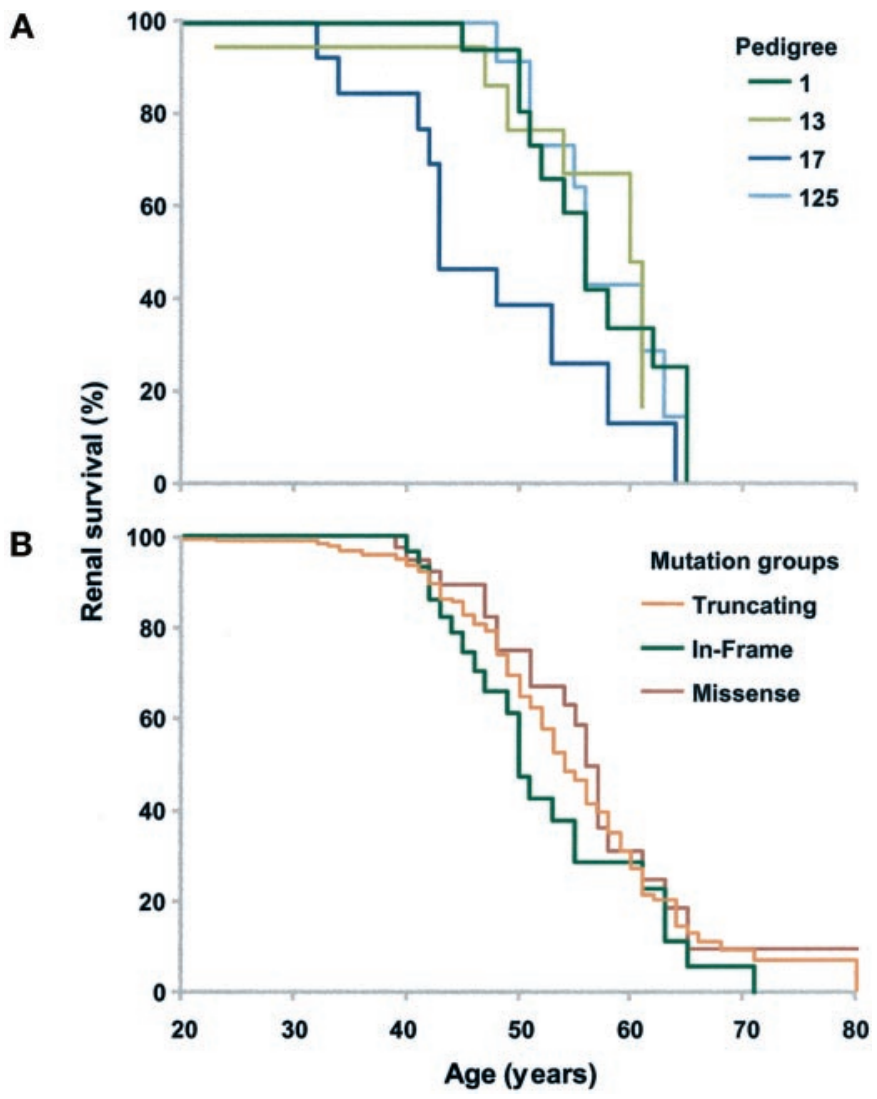

Figure 3. Renal survival plots showing (A) significant differences in renal survival among four different PKD1 families with greater than 17 patients (mutations: P1; IVS7+1G $\rightarrow$ A; P13, C2229X; P17/P17A, Q2243X, and P125, E3631D) and (B) no significant influence of mutation type (truncating, in-frame, and missense).

ever, account for some of the interfamilial differences, although a single factor would not be expected to have a strong influence in these large, multi-generation families.

\section{Analyses of the PKD1 Mutation}

To test whether characteristics of the mutation were associated with the severity of disease, renal survival plots were compared among different mutation types: (1) truncating mutations; (2) in-frame changes; and (3) missense events; however, no significant differences were found (Figure 3B and Table 1). Second, the importance of the mutation's location was tested in terms of the nucleotide position along the gene with the patients separated into two groups at the median position (nucleotide 7812; exon 19). Renal survival plots comparing the two populations showed that the 5 ' group (0 to $7812 \mathrm{nt}$ ) had significantly more severe disease $(P=0.025$; Figure 4A). Analysis of the plot of age at ESRD compared with mutation position demonstrated the same result (without taking censoring into account), with the mean age at ESRD lower at the $5^{\prime}$ than at the 3 ' end (Figure 2). This difference was also reflected in the median age to ESRD and probabilities of renal survival at various ages (see Table 1 for details). Of six patients with ESRD by $35 \mathrm{yr}$, all were in the 5' group (Figure 2). To determine the significance of mutation location more clearly,
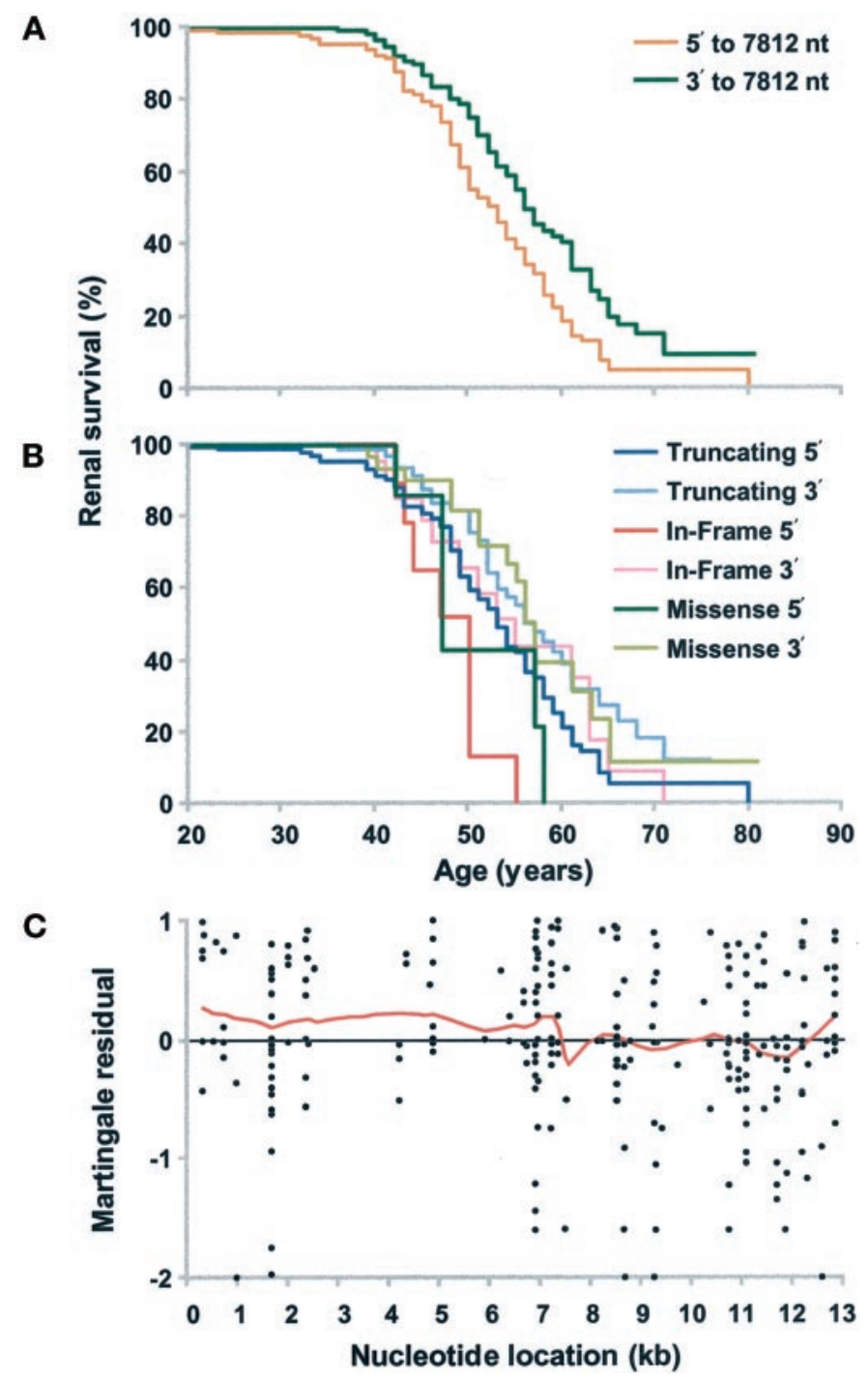

Figure 4. Renal survival plots comparing (A) patients with mutations in the 5' region of the gene (0 to $7812 \mathrm{nt}$ ) compared with the 3' group and (B) each mutation type (truncating, in-frame, and missense) divided at nucleotide position 7812. (C) Plot of Martingale residuals of the Cox model against nucleotide position showing a running average (red line) and zero position (black line). The overall average residual is zero with positive values, as seen in the 5' area, indicating an excess of ESRD relative to expected. All 324 patients are included, with only ESRD patients having positive residuals. Patients with location less than the median (7812) were found to have an earlier onset of ESRD (Table 1). Hence, the purpose of this exploratory analysis is to use the running average to estimate more precisely the location of a change in ESRD risk. The figure suggests a change in risk around 7 to $8 \mathrm{~kb}$, near the median location. (Four points with values less than -2 are shown on the -2 axis).

data for each of the three mutation types was divided at the median position and analyzed separately (Figure 4B and Table 1). This analysis showed that location was associated with severity of renal disease in each case, with the three 5' populations associated with more severe disease than their $3^{\prime}$ counterparts, although statistical significance was only achieved for the in-frame mutations. 
To assess whether the change in disease severity along the gene was a gradual gradient or associated with a specific cut point, the Martingale residuals from a Cox model with no covariates were plotted against nucleotide position (Figure 4C). In this analysis, the zero score represents an average likelihood of developing ESRD, with patients plotted above the line developing ESRD earlier than the average and those below the line having less severe disease. The running average shows a greater likelihood of ESRD in the 5' population and a cut point to less ESRD at about 7 to $8 \mathrm{~kb}$, indicating that the median position (7812 nt) is a reasonable estimate of the point of change.

\section{Families with Atypical Renal Presentation}

The penetrance of the PKD1 phenotype, when ESRD is considered an end point, is very high (Figure 1). However, two families in whom comprehensive histories were available had consistently mild cystic disease (see Materials and Methods). Although mutation position is an indicator of disease severity in the whole population, this does not seem to explain these extreme cases, as one had a $5^{\prime}$ mutation and one had a $3^{\prime}$ change. It is possible in these cases that unusual characteristics of the mutation, such as an ability to generate a partially functional polycystin-1 from $P K D 1$ with a missense mutation (P228), may explain the mild disease. In the other family (P499), the mutation is a nonsense change early in the gene and mosaicism is possible in the father, as he has an apparent negative family history. This was, however, not evident in leukocyte DNA, and his son also had mild disease.

This study contained six pedigrees including one early onset case. Two of these pedigrees had mutations in the $5^{\prime}$ region, and four had mutations in the 3' area and were of various types (see Materials and Methods) and so the position or type of these changes was not a good indicator of early onset disease. Two of these changes were also found in families with more typical disease (28), and there is clear intrafamilial phenotypic variability in the early-onset families (see Materials and Methods for clinical details).

\section{Discussion}

We have analyzed renal disease severity in a large and highly characterized cohort of PKD1 families. The median age at the onset of ESRD or death of $53 \mathrm{yr}$ was similar to other studies (16), with a slightly higher age for ESRD alone (54 yr). This difference reflects death from nonrenal PKD1-related problems, such as subarachnoid hemorrhage and cardiovascular disease, as well as early non-PKD1 related deaths. Consistent with other PKD1 studies, gender was not found to correlate significantly with disease severity (16). This finding differs from some previous studies (34) of the entire ADPKD population, which found significantly more severe disease in men. One explanation for the difference between these studies may be an influence of gender that has been noted in PKD2 (16).

One of the strongest conclusions that can be drawn from this study is that the presentation of the disease is highly variable, with marked differences in disease severity seen within individual families. This is consistent with previous studies that have shown significant intrafamilial variation using measures of renal func- tion, renal size, and age at the onset of $\operatorname{ESRD}(17,18,35)$. This variation presumably reflects the significant influence of genetic modifying factors and environment on disease presentation and progression. One possible group of modifying factors are ones that effect the frequency of somatic second hits and therefore modulate the rate of cyst initiation or influence the course of cyst development (36). Genetic modifying factors have been mapped in various rodent models of polycystic kidney disease and are likely to be important in PKD1 (37-39). Two previous studies of PKD1 populations suggested that the ACE polymorphism might be a significant modifier $(20,21)$, with an association between severe renal disease and the DD haplotype; one study found no correlation (40). In our population, no association was found between the ACE genotype and severity of renal disease, indicating that here the ACE polymorphism is not a significant modifying factor. Extremes of intrafamilial variability were particularly evident in families with an early onset case of disease. The evidence presented here of a wide variety of different mutations associated with early presentation, the documented variability within families, and recurrence risk in siblings indicates that one or a small number of modifying factors $(12,19)$, or possibly an early somatic event, are likely to strongly influence the disease presentation in these cases. Likewise, special factors, such as only partially inactivating mutations or mosaicism (although this could not explain mild disease in multiple generations) may be important in pedigrees with late-onset PKD1.

The large size of the study population and the available mutation data allowed genotype/phenotype correlations in PKD1 to be addressed for the first time. The most important finding from this analysis was that the position of the PKDI mutation influenced the severity of renal disease. The effect was modest compared with the total amount of variability; however, it was statistically significant in the total population. It is unlikely that other factors accounted for the association between position and severity of renal disease. Neither gender $(P=0.52)$ nor hypertension $(P=0.69)$ were significantly different between the $5^{\prime}$ and $3^{\prime}$ populations, and the ACE haplotype was not associated with severity of renal disease $(P$ $=0.26$ ). The effect of the mutation location can be seen in the plot of age at ESRD, with the running average moving upward from the 5' to 3 ' end, and the average value changing from a minimum of $49 \mathrm{yr}$ in the $5^{\prime}$ region to a maximum of $54 \mathrm{yr}$ in the 3' area (Figure 2). This effect is, however, more clearly seen in a renal survival plot when data from all patients is included (Figure 4A), with a significant difference seen between the $5^{\prime}$ and 3' populations. The difference is expressed in the finding that ESRD occurs, on average, two to five years earlier in the 5' population between 25 to $70 \mathrm{yr}$, with a more pronounced difference as age progresses (Table 1). The plot of Martingale residuals gave support to the hypothesis that a position of 7 to $8 \mathrm{~kb}$ along the gene (close to the median location) marks a cut point between more severe and a milder disease outcome.

Finding that the location of the mutation significantly influences the phenotype may have implications for understanding the disease mechanism. It has been widely assumed, consistent with the two-hit hypothesis, that regardless of type or position, the germline mutation simply inactivates a PKDI allele. A cyst 
subsequently develops in the absence of polycystin-1 following a second inactivating mutation (36). However, the finding that the location of the mutation influences the disease course suggests that some product can be generated from the mutant allele. Interestingly, previous studies of the mutant PKDl gene have shown that the abnormal transcript is usually stable (not susceptible to nonsense-mediated mRNA decay), suggesting that the mutant gene may generate a functional product (28).

A possible explanation for the more severe disease associated with $5^{\prime}$ mutations is that they generate a dominant negative product. This would be consistent with the more severe disease associated with 5' in-frame cases (Figure 4B). However, analysis of a family with a truncating mutation at the extreme 5' end (P103, 224del13; 28), which is unlikely to generate an abnormal product, shows that the affected members develop ESRD at a mean age of $47 \mathrm{yr}$ (4 events) and hence appear to have the severe 5' phenotype. These data seem to indicate that loss of a product rather than a dominant negative effect may be important. More than one protein may be generated from the PKDI gene, and the locationassociated phenotypic difference could be because $5^{\prime}$ and $3{ }^{\prime}$ mutations disrupt different products. Possible sites of splicing or cleavage close to the proposed phenotypic cut site (7 to $8 \mathrm{~kb}$; exons 15 to 20 in the REJ or GPS regions of the protein) have been described $(3,4,41)$. Recent comparison of two targeted disruptions of murine $P k d l$ (in the 5 ' region, exon 4; $P k d l^{\text {null }}$ and $3^{\prime}$ region, exon 34; $P k d l^{\text {del34}}$ ) showed that the 5 ' mutant had a more severe phenotype in the homozygous and heterozygous animals (42). Furthermore, although the $5^{\prime}$ mutant did not generate a polycystin-1 product when analyzed with an $\mathrm{N}$-terminal antibody, a polycystin-1 product was seen in the del34 mutant, indicating that the location of the mutation may influence the polycystin-1 products generated. Disruption of an N-terminal product may be more deleterious, and disruption of the relative abundance of different splicing/cleavage products may be critical, as occurs at the WT1 locus (43-45). Recently, evidence that polycystin-1 dosage may be important for normal renal development has been described (46).

This study indicates that, despite the variability of the PKD1 phenotype, the position of the mutation influences the renal phenotype. Discovering the precise mechanism by which $5^{\prime}$ and $3^{\prime}$ mutations have different phenotypic effects will require experimental approaches as well as further epidemiologic data. Nevertheless, this observation indicates that renal cystic disease in PKD1 results from more than simple loss of all polycystin-1 products.

\section{Acknowledgments}

We thank Drs. Lesley Rees and Sushmita Roy, London, UK; Dr. Albert O. M. Ong, Sheffield, UK; and Drs. Peter J. Ratcliffe and Tricia Boyd, Oxford, UK for supplying samples and clinical information on their patients. We also thank the patients and their families for taking part in the study, Vicki Gamble for genotyping analysis, C. Strong for data collection, and Jeffrey Slezak for statistical analysis. This work was supported by NIDDK Grant RO1 DK58816, The Medical Research Council (UK), The Mayo Foundation, The PKD Foundation, Telethon, Italy, NATO/Royal Society (UK), and the Oxford Kidney Unit Trust Fund.

\section{References}

1. Dalgaard OZ: Bilateral polycystic disease of the kidneys: A follow-up of two hundred and eighty-four patients and their families. Acta Med Scand 328: 1-255, 1957

2. European Polycystic Kidney Disease Consortium: The polycystic kidney disease 1 gene encodes a $14 \mathrm{~kb}$ transcript and lies within a duplicated region on chromosome 16. Cell 77: 881-894, 1994

3. Hughes J, Ward CJ, Peral B, Aspinwall R, Clark K, San Millán JL, Gamble V, Harris PC: The polycystic kidney disease 1 $(P K D 1)$ gene encodes a novel protein with multiple cell recognition domains. Nature Genet 10: 151-160, 1995

4. International Polycystic Kidney Disease Consortium: Polycystic kidney disease: The complete structure of the PKDl gene and its protein. Cell 81: 289-298, 1995

5. Mochizuki T, Wu G, Hayashi T, Xenophontos SL, Veldhusien B, Saris JJ, Reynolds DM, Cai Y, Gabow PA, Pierides A, Kimberling WJ, Breuning MH, Deltas CC, Peters DJM, Somlo S: PKD2, a gene for polycystic kidney disease that encodes an integral membrane protein: Science 272: 1339-1342, 1996

6. Hanaoka K, Qian F, Boletta A, Bhumia AK, Piontek K, Tsiokas L, Sukhatme VP, Guggino WB, Germino GG: Co-assembly of polycystin-1 and-2 produces unique cation-permeable currents. Nature 408: 990-994, 2000

7. Gonzalez-Perrett S, Kim K, Ibarra C, Damiano AE, Zotta E, Batelli M, Harris PC, Resin IL, Arnaut MA, Cantiello HF: Polycystin-2, the protein mutated in autosomal dominant polycystic kidney disease (ADPKD), is a $\mathrm{Ca}^{2+}$-permeable non-selective cation channel. Proc Natl Acad Sci USA 98: 1182-1187, 2001

8. Vassilev PM, Guo L, Chen XZ, Segal Y, Peng JB, Basora N, Babakhanlou H, Cruger G, Kanazirska M, Ye CP, Brown EM, Hediger MA, Zhou J: Polycystin-2 is a novel cation channel implicated in defective intracellular $\mathrm{Ca}^{2+}$ homeostasis in polycystic kidney disease. Biochem Biophys Res Commun 282: 341350, 2001

9. Huan Y, van Adelsberg J: Polycystin-1, the PKD1 gene product, is in a complex containing E-cadherin and the catenins. J. Clin. Invest. 104: 1459-1468, 1999

10. Wilson PD, Geng L, Li X, Burrow CR: The PKD1 gene product, "polycystin-1" is a tyrosine-phosphorylated protein that colocalizes with $\alpha 2 \beta 1$-integrin in focal clusters in adherent renal epithelia. Lab Invest 79: 1311-1323, 1999

11. Somlo S, Ehrlich B: Human disease: Calcium signaling in polycystic kidney disease. Curr Biol 11: R356-R360, 2001

12. Zerres K, Rudnik-Schöneborn S, Deget F, German working group on paediatric nephrology: Childhood onset autosomal dominant polycystic kidney disease in sibs: clinical picture and recurrence risk. J Med Genet 30: 583-588, 1993

13. Fick GM, Johnson AM, Strain JD, Kimberling WJ, Kumar S, Manco-Johnson ML, Duley IT, Gabow PA: Characteristics of very early onset autosomal dominant polycystic kidney disease. J Am Soc Neph 3: 1863-1870, 1993

14. Gabow PA, Johnson AM, Kaehny WD, Kimberling WJ, Lezotte DC, Duley IT, Jones RH: Factors affecting the progression of renal disease in autosomal-dominant polycystic kidney disease. Kidney Int 41: 1311-1319, 1992

15. Peters DJM, Sandkuijl LA: Genetic heterogeneity of polycystic kidney disease in Europe. In: Contributions to Nephrology: Polycystic Kidney Disease, Vol. 97, edited by Breuning, MH, Devoto M, Romeo G, Basel, Karger, 1992, pp 128-139

16. Hateboer N, van Dijk MA, Bogdanova N, Coto E, Saggar-Malik AK, San Millan JL, Torra R, Breuning M, Ravine D: Compari- 
son of phenotypes of polycystic kidney disease types 1 and 2 . Lancet 353: 103-107, 1999

17. Milutinovic J, Rust PF, Fialkow PJ, Agodoa LY, Phillips LA, Rudd TG, Sutherland S: Intrafamilial phenotypic expression of autosomal dominant polycystic kidney disease. Am J Kid Dis 19: 465-472, 1992

18. Geberth S, Ritz E, Zeier M, Stier E: Anticipation of age at renal death in autosomal dominant polycystic kidney disease (ADPKD)? Nephrol Dial Transpl 10: 1603-1606, 1995

19. Peral B, Ong ACM, San Millán JL, Gamble V, Rees L, Harris PC: A stable, nonsense mutation associated with a case of infantile onset polycystic kidney disease 1 (PKD1). Hum Mol Genet 5: 539-542, 1996

20. Baboolal K, Ravine D, Daniels J, Williams N, Holmans P, Coles GA, Williams JD: Association of the angiotensin I converting enzyme gene deletion polymorphism with early onset of ESRF in PKD1 adult polycystic kidney disease. Kidney Int 52: 607-613, 1997

21. Perez-Oller L, Torra R, Badenas C, Mila M, Darnell A: Influence of the ACE gene polymorphism in the progression of renal failure in autosomal dominant polycystic kidney disease. Am J Kidney Dis 34: 273-278, 1999

22. Hateboer N, Lazarou LP, Williams AJ, Holmans P, Ravine D: Familial phenotype differences in PKD1. Kidney Int 56: 34-40, 1999

23. Pei Y, Paterson AD, Wang KR, He N, Hefferton D, Watnick T, Germino GG, Parfrey P, Somlo S, St. George-Hyslop P: Bilineal disease and trans-heterozygotes in autosomal dominant polycystic kidney disease. Am J Hum Genet 68: 355-363, 2001

24. Ryynanen M, Dolata MM, Lampainen E, Reeders ST: Localisation of a mutation producing autosomal dominant polycystic kidney disease without renal failure. J Med Genet 24: 462-465, 1987

25. Hateboer N, Veldhuisen B, Peters D, Breuning MH, San-Millan JL, Bogdanova N, Coto E, von Dijk MA, Afzal AR, Jeffery S, SaggarMalik AK, Torra R, Dimitrakov D, Martinez I, de Castro SS, Krawczak M, Ravine D: Location of mutations within the PKD2 gene influences clinical outcome. Kidney Int 57: 1444-1451, 2000

26. Watnick T, Phakdeekitcharoen B, Johnson A, Gandolph M, Wang M, Briefel G, Klinger KW, Kimberling W, Gabow P, Germino GG: Mutation detection of PKD1 identifies a novel mutation common to three families with aneurysms and/or veryearly-onset disease. Am J Hum Genet 65: 1561-1571, 1999

27. Jais JP, Knebelmann B, Giatras I, De Marchi M, Rizzoni G, Renieri A, Weber M, Gross O, Netzer KO, Flinter F, Pirson Y, Verellen C, Wieslander J, Persson U, Tryggvason K, Martin P, Hertz JM, Schroder C, Sanak M, Krejcova S, Carvalho MF, Saus J, Antignac C, Smeets H, Gubler MC: X-linked Alport syndrome: Natural history in 195 families and genotype- phenotype correlations in males. J Am Soc Nephrol 11: 649-657, 2000

28. Rossetti S, Strmecki L, Gamble V, Burton S, Sneddon V, Peral B, Roy S, Bakkaloglu A, Komel R, Winearls C, Harris PC: Mutation analysis of the entire PKDl gene: Genetic and diagnostic implications. Am J Hum Genet 68: 46-63, 2001

29. Ravine D, Gibson RN, Walker RG, Sheffield LJ, Kincaid-Smith P, Danks DM: Evaluation of ultrasonographic diagnostic criteria for autosomal dominant polycystic kidney disease 1. Lancet 343: 824-827, 1994
30. Zerres K, Volpel M-C, Wei BH: Cystic kidneys. Hum Genet 68: $104-135,1984$

31. Cox DR: Regression models and life-tables. J Royal Statist Soc 34: 187-220, 1972

32. Wei L, Lin DY, Weisserfeld L: Cox regression model; proportional-hazards; simultaneous inference. J Am Statist Assoc 84: 1074-1078, 1989

33. Therneau TM, Grambsch PM: Modeling Survival Data: Extending the Cox Model. New York, Springer, 2000

34. Gretz N, Zeier M, Geberth S, Strauch M, Ritz E: Is gender a determinant for evolution of renal failure? A study in autosomal dominant polycystic kidney disease. Am J Kidney Dis 14: 178-183, 1989

35. Fick GM, Johnson AM, Gabow PA: Is there evidence for anticipation in autosomal-dominant polycystic disease? Kidney Int. 45: 1153-1162, 1994

36. Qian F, Watnick TJ, Onuchic LF, Germino GG: The molecular basis of focal cyst formation in human autosomal dominant polycystic kidney disease type 1. Cell 87: 979-987, 1996

37. Woo DDL, Nguyen DKP, Khatibi N, Olsen P: Genetic identification of two major modifier loci of polycystic kidney disease progression in PCY mice. J Clin Invest 100: 1934-1940, 1997

38. Iakoubova OA, Dushkin H, Beier DR: Localization of a murine recessive polycystic kidney disease mutation and modifying loci that affect disease severity. Genomics 26: 107-114, 1995

39. Guay-Woodford LM, Wright CJ, Walz G, Churchill GA: Quantitative trait loci modulate renal cystic disease severity in the mouse bpk model. J Am Soc Nephrol 11: 1253-1260, 2000

40. van Dijk MA, Breuning MH, Peters DJM, Chang PC: The ACE insertion/deletion polymorphism has no influence on progression of renal function loss in autosomal dominant polycystic kidney disease. Neph Dial Transplant 15: 836-839, 2000

41. Ponting CP, Hofmann K, Bork P: A latrophilin/CL-1-like GPS domain in polycystin-1. Curr Biol 9: R585-R588, 1999

42. Lu W, Shen X, Pavlova A, Lakkis M, Ward CJ, Pritchard L, Harris PC, Genest DR, Perez-Atayde AR, Zhou J: Comparison of Pkdl-targeted mutants reveals that loss of polycystin- 1 causes cystogenesis and bone defects. Hum Mol Genet 10: 2385-2396, 2001

43. Little M, Holmes G, Bickmore W, van Heyningen V, Hastie N, Wainwright B: DNA binding capacity of the WT1 protein is abolished by Denys-Drash syndrome WT1 point mutations. Hum Mol Genet 4: 351-358, 1995

44. Klamt B, Koziell A, Poulat F, Wieacker P, Scambler P, Berta P, Gessler M: Frasier syndrome is caused by defective alternative splicing of WT1 leading to an altered ratio of WT1 +/-KTS splice isoforms. Hum Mol Genet 7: 709-714, 1998

45. Liu JJ, Wang ZY, Deuel TF, Xu YH: Imbalanced expression of functionally different WT1 isoforms may contribute to sporadic unilateral Wilms' tumor. Biochem Biophys Res Commun 254: 197-199, 1999

46. Pritchard L, Sloane-Stanley JA, Sharpe J, Aspinwall R, Lu W, Buckle V, Strmecki L, Walker D, Ward CJ, Alpers CE, Zhou J, Wood WG, Harris PC: A human PKDl transgene generates functional polycystin-1 in mice and is associated with a cystic phenotype. Hum Mol Genet 9: 2617-2627, 2000

\section{Access to UpToDate on-line is available for additional clinical information at http://www.jasn.org/}

